\title{
The Metaphorical Use of Collocations: A Corpus-Based Study
}

\author{
Yanqin Cheng ${ }^{1}$ \\ ${ }^{1}$ School of Foreign Languages, Beihang University, Beijing, China \\ Correspondence: Yanqin Cheng, School of Foreign Languages, Beihang University, 37 Xueyuan Road, Haidian \\ District, Beijing, China. E-mail: chengyanqin@buaa.edu.cn
}

\author{
Received: February 26, 2019 Accepted: March 22, 2019 Online Published: April 6, 2019 \\ doi:10.5539/ijel.v9n3p107 URL: https://doi.org/10.5539/ijel.v9n3p107
}

\begin{abstract}
The meanings of collocations, which have been accepted as an abstraction at the syntagmatic level, may have been defined by the way human beings conceptualize the world. The patterns in the use of the English word "contain" are summarized using the British National Corpus and an attempt is made to use conceptual metaphors to interpret how these patterns came into being and how they could have derived from human beings' earliest bodily experience in the physical world. Such insight into English collocations may help improve the teaching of collocations to EFL learners.
\end{abstract}

Keywords: collocation, corpus-based, conceptual metaphor, image schemata, EFL learner

\section{Introduction}

The late twentieth century and early twenty-first century has witnessed the emergence and rapid development of both corpus linguistics and cognitive linguistics, which have opened new dimensions in the study of linguistics. Corpus linguistics employs empirical evidence to examine how language is used in reality and what they reveal about language use and cognitive linguistics aims at establishing the link between language and the way humans perceive and interact with the world. Both emphasize the importance of language in use and the combination of the two will undoubtedly throw more light on language use. Studies conducted in the past, however, were, more or less, confined either to corpus linguistics or to cognitive linguistics. And renowned corpus linguists like Wolfgang Teubert once explicitly expressed the impossibility of integrating corpus linguistics and cognitive linguistics. Teubert believed that the latter is flawed in at least one of its basic assumptions, that is, meaning is governed by man's conceptualization of the world. They maintain that meaning can only be generated in actual language use, depending on the context (Teubert, 2010). In recent years, however, attempts have been made to integrate the methodologies and discoveries in both fields and interesting findings have been produced (Deignan, 2005; Gries, 2006; Stefanowitsch, 2006; Glynn \& Fischer, 2010). The present study is also an attempt to bring the two fields together to gain new insights into the use of English words, especially by combining the study of collocation in corpus linguistics with Lakoff and Johnson's research findings in the study of conceptual metaphors.

In Metaphors We Live By, George Lakoff and Mark Johnson argue that metaphors, previously believed to be merely "a device of the poetic imagination", are actually quite pervasive in our everyday life. They exist not only in the language we use but also in our thought and action. They reflect "what we perceive, how we get around in the world, how we relate to other people" and form an important part of the conceptual system that defines "our everyday realities". Two categories of metaphors are identified by the two authors, namely, primary metaphors "that are directly grounded in the everyday experience that links our sensory-motor experience to the domain of our subjective judgments" like MORE IS UP and complex metaphors that are developed based on primary metaphors. The metaphors derived from our experience of spatial orientation are defined as orientational metaphors. And most of our basic concepts are believed to be organized in terms of spatialization metaphors. "Our experience of physical objects and substances" gives rise to another set of metaphors, "entity and substance metaphors", also known as "ontological metaphors". These metaphors enable us to understand events, activities, emotions and ideas in terms of objects and substances, either discrete and bounded naturally or by artificial means. By means of metaphors, many of the experiences that are not directly experiential or are simply in our conceptual thinking become referable, identifiable and quantifiable (Lakoff \& Johnson, 2003). 
The term collocation has been studied and further defined by a number of linguists since it was first used by Firth (1957). And the general consensus is that it refers to "the characteristic co-occurrence of patterns of words" (Xiao \& Mcenery, 2006, p. 105). As to meaning, Firth asserted that "meaning by collocation is an abstraction at the syntagmatic level and is not directly concerned with the conceptual or idea approach to the meaning of words" (Firth, 1957, p. 196). That is, meaning is not imbedded in individual words, especially as far as collocations are concerned, but is derived from the collocates with which they co-occur. In Firth's words, "You shall know a word by the company it keeps."

The importance of teaching collocations, especially to EFL learners, has been widely recognized. One key objective of corpus linguists, according to Wolfgang Teubert, is to address "concrete needs in the teaching of English as a foreign language." And it "is these units (collocates) that a language learner has to grasp if they want to speak the target language properly" (Teubert, 2010, p. 24). But as Awaj (2018) points out, "despite the extensive research on collocations ..., the development of L2 collocational knowledge is still ... challenging for non-native speakers". So far, studies of collocation, either at the lexical or the grammatical level, remain largely content to discover certain collocations or even colligation patterns and/or determine the semantic prosodies these patterns may reveal. Few studies have come up with very effective methods to help students to master the large number of collocations in the English language. Fewer studies have attempted to address this issue from the perspective of conceptual metaphors. Wu (2014) does claim to adopt a cognitive approach, but the study remains largely theoretical. The present paper attempts to look at how the discoveries concerning conceptual metaphors can actually throw light on why certain collocates are preferred by certain words. Hopefully, such studies could help EFL learners gain more insights into English collocations and improve their use of the English language. The word "contain" has been chosen, due to the fact that it is often used both experientially and metaphorically as defined by cognitive linguists. The paper will first examine the collocates that often co-occur with the word and then try to use Lakoff and Johnson's concepts of metaphors to examine why these collocates have been selected, or rather, why "contain" has been selected by these collocates.

\section{Methodology and Results}

Since the present study is to examine how certain collocations of English words, "contain" in this particular case, might have been determined conceptually before they entered discourse, the collocations of the given word have to be identified first and then these collocations are to be understood in light of conceptual metaphors.

To generate the collocations of "contain", the online British National Corpus (BNC) is used. BNC is a 100-million-word corpus of written and spoken language from a wide range of sources, from regional and national newspapers, specialist periodicals and journals, academic books and popular fiction, among many other kinds of text. It also contains orthographic transcriptions of unscripted informal conversations (recorded by volunteers selected from different age, region and social classes in a demographically balanced way) in different contexts (Retrieved from http://sla.sjtu.edu.cn/www/43/2008-06/67.html).

To reduce the entries to a manageable size, only entries containing "contain the" are kept, leaving us with a total number of 515 entries. And of the 515 entries, only the first of every five entries, 103 in total, are left for analysis.

A close study of the 103 entries reveals the following major usages of the word "contain":

Example 1: ... most Land Rovers on routine calls only contain the driver and observer, both seated in the front, ...

Example 2: In the church a carved stone shrine was erected to contain the saint's relics.

In these two examples, the subject is a container with a physical existence and the object being contained is also an object, substance or living creature with proper physical dimensions. The existence of both the subject and the object can be verified not only spatially but also temporally. The object, however, is not an integral part of the subject. They come together either by chance or by choice. This usage of "contain" is designated as Usage 1 and the usages to be discussed hereafter are designated as Usage 2, Usage 3, etc. respectively.

Example 3: the dough on greased baking sheets, raising the edges of each piece slightly to contain the topping. 5. Spoon the pizza sauce onto the dough and top with

Example 4: only a tight white brassire above her skirt. It seemed almost too small to contain the swelling plumpness of her upper body. It crushed and lifted her breasts to

In Examples 3 and 4, the subject is an object that can function as a container that could have some other object(s) or substance(s) within it (Usage 2). 
Example 5: Croton sublyratus, which is used in traditional medicine, has recently been found to contain the antiulcer acyclic terpenoid plaunotol which is similar in structure to gefarnate ...

Example 6: ... lotions would be displayed in simple bottles of all shapes and sizes and which would contain the natural ingredients she had come across during her trips to remote communities.

Example 7: In its amalgamated form, the Physical and Theoretical Chemistry Laboratory will contain the Dr Lee's and Coulson Professors, the ad hominem Professor of Electron Spectroscopy ...

In Examples 5, 6, 7 the subject is an entity or substance, of which the contained is but a component, element, ingredient or member. Both the subject and the contained have a physical existence. But the relationship between the subject and the object(s) is that of the whole and its part(s) (Usage 3).

Example 7 is a bit tricky, for the relationship between the laboratory and the professors seem to be that of the container and the contained in spatial terms, but a closer look at the sentence reveals that the laboratory here does not refer to the physical environment in which scientific experiments are conducted, but the people who man the laboratory.

Example 8: ... must not contain the "FOREIGN-SET-IS" keyword, nor any user-supplied entries.

In Example 8, the subject is a document, essay, or other written composition. The objects contained are words, sentences, paragraphs or figures, tables, pictures, etc. that constitute the text. Both the subject and the object can be seen as having a physical existence for they are concrete symbols, though man-made, to represent meaning or information (Usage 4).

Example 9: The pleadings are somewhat convoluted but must be referred to because they contain the facts, as is normal in a demurrer.

Example 10: ... if it can be shown that the written document was not intended to contain the whole of the parties' agreement ...

In the above two examples, the subject is a document, essay, or other written composition. The objects contained are words, sentences, paragraphs or figures, tables, pictures, etc. that constitute the text. Both the subject and the object are recognized as something other than what they are taken as literally, meaning mere words, sentences, passages, etc. They are symbols which, when combined, refer to concepts more abstract than the symbols themselves (Usage 5).

Example 11: Effective learning requires a certain simplicity of structure in which to contain the openness and indefiniteness of all genuine learning.

Example 12: or incident in the first half of the month or around the 27th may well contain the seeds of something far greater. Certainly, Venus protects your interests while the planetary ...

Example 13: attributes, a part of the price of each drawing will remain unexplained, and contain the influence of time (the trend, if any), as well as ...

Example 14: to be considered reasonable value. Third, the target bank's business mix must contain the inherent value to repay the premium that the acquirer will have to pay to ...

In Examples 11 through 14, the object is a quality, value, or possibility that the subject exhibits or is assumed to possess (Usage 6).

Example 15: Mortimer reholstered his gun, satisfied at a job well done, and striving to contain the excitement he felt at the combat. He spotted a familiar face, and

In the above example: the subject is a human being and the object is a kind of mental or psychological condition or conduct which seems to arise from inside the human body. If left unchecked, this condition or conduct may go beyond a limit not under regular control (Usage 7).

Example 16: ... Order Act, which became law on 1 January 1937, in an attempt to contain the situation.

Example 17: ... Helmut Kohl's government, which has been accused of not trying hard enough to contain the wave of Right-wing violence.

In Examples 16, 17, the subject is an agent, while the object is an unfavorable condition, situation or state of affairs whose spread, expansion or influence has to be checked to prevent further harm or damages (Usage 8).

So far, 8 major usages of "contain" have been identified, to verify which a check will be necessary. To this end, WordNet 2.1 is used. 
By running the word "contain" on WordNet 2.1, a lexical database of English developed under the direction of George A. Miller of Princeton University, the verb is found to have 6 senses (first 3 from tagged texts):

a. (119) incorporate, contain, comprise - (include or contain; have as a component; "A totally new idea is comprised in this paper"; "The record contains many old songs from the 1930's")

b. (39) hold, bear, carry, contain - (contain or hold; have within; "The jar carries wine"; "The canteen holds fresh water"; "This can contain water")

c. (2) control, hold in, hold, contain, check, curb, moderate - (lessen the intensity of; temper; hold in restraint; hold or keep within limits; "moderate your alcohol intake"; "hold your tongue"; "hold your temper"; "control your anger")

d. contain- (be divisible by; "24 contains 6")

e. contain, take, hold - (be capable of holding or containing; "This box won't take all the items"; "The flask holds one gallon")

f. check, turn back, arrest, stop, contain, hold back- (hold back, as of a danger or an enemy; check the expansion or influence of; "Arrest the downward trend"; "Check the growth of communism in South East Asia"; "Contain the rebel movement"; "Turn back the tide of communism")

Of the six senses provided by WordNet 2.1, b corresponds to Usage 1, e to Usage 2; a corresponds to Usages 3, 4 and 5; $\mathrm{c}$ and $\mathrm{f}$ correspond to Usages 7 and 8 respectively. Usage 6 is fascinating because it fits none of the 6 senses. And conversely, sense $d$ is not found in the selected data. But by and large the usages thus abstracted correspond to the common ways that the word "contain" is found to be used. And they represent the common ways in which the word is used and can be taken as quite reliable.

\section{Analysis and Discussion}

Lakoff and Johnson believe that "our conceptual system is largely metaphorical" and "the essence of metaphor is understanding and experiencing one kind of thing in terms of another" (Lakoff \& Johnson, 2003). That is, metaphors represent how human beings understand and experience one thing in the way they understand and experience another. Lakoff and Johnson have found that language, to a great extent, reveals how our conceptual system works. The same or similar words or expressions can often be found to describe two things, ideas or activities that fall into different domains. For example, he attacked every weak point in my argument. His criticisms were right on target (Lakoff \& Johnson, 2003). In the same way, the eight usages of the word "contain" can also be found to represent how human beings have gradually extended the use of the word from one situation to another metaphorically.

"Contain" is by definition a polysemous word. Johnson (1987, xii) asserts that "polysemy involves the extension of a central sense of a word to other senses by devices of human imagination". By imagination, Johnson meant "imaginative understanding" or "imaginative structures", the way "human meaning and understanding" grows out of bodily experience. The embodied imaginative structure is metaphor. Metaphors are important to human knowledge for "through metaphor, we make use of patterns that we obtain in our physical experience to organize our more abstract understanding" (Johnson, 1987, xv). This roughly reflects how the central sense of the word "contain" is extended gradually to make it a polysemous word used in multiple patterns. Or in other words, the word "contain" came to be used the way it is because of human beings' "imaginative understanding" and the application of "conceptual metaphors".

Of the 8 usages of "contain" abstracted, the first can be regarded as deriving from the central sense of the word, which is most closely related to human beings' experience of the physical world, or the image schemata. In Lakoff and Johnson's words, this sense derives from our direct experience of space and orientation. But the other senses are far from being arbitrary. In Johnson's words, they are the metaphorical projections of the image schemata.

According to the online etymology, the word "contain" comes from an old French word "contenir" and the Latin word "continere", meaning "to hold together, enclose". This sense must have come from mankind's first conceptualization of space. Like UP and DOWN, inside-outside are among the basic spatial concepts that our ancestors must have mastered through their repeated bodily experience of the physical world. This knowledge is based on human beings' observation and recognition of verticality, horizontality as well as other spatial relationships between objects, summed up as the image schemata by Johnson. That could explain the first and basic usage of contain (Usage 1), with a container enclosing a space in which the contained can be put or found. This container could initially be seen as physical and having an enclosed space. In this usage, the container and 
the contained are distinct objects that come together by chance or by choice. The removal of the contained will leave the container intact. Then this usage is extended to indicate the ability of a container to keep the contained within the space it encloses (Usage 2). But the relationship between the container and the contained remains identical to that in Usage 1.

Still from the first usage comes Usage 3 with the enclosed space extended to include the capacity of the subject as the whole to have the contained as its components, ingredients or members. The whole is regarded as a container and the components, ingredients or members are seen as comprising the whole. The removal of the contained, of course, can lead to some changes in the whole, either in size, amount, or even in property.

From Usage 3 derives Usage 4 in which the whole becomes a text, the components of which include words, sentences, paragraphs or figures, tables, pictures, etc. The enclosed space refers to the capacity of each text to hold the components within it. Here the word "text" is used broadly to include also what is called hypertext in the Internet era. The texts are seen as the sum of these man-made symbols. These symbols are further conceptualized as indicating concepts more abstract, such as agreement, contract, etc. What are deemed as an agreement, contract, or declaration of war could have been determined by convention or some other means and have thereafter been spread through common consensus, instruction or rule of law, thus giving rise to Usage 5 .

Usage 6 is similar to Usage 3 in the sense that both involve the subject as an entity, a whole. But the difference lies in the fact in Usage 6 what is contained is not a component, an ingredient or member but a quality, color, value, or possibility that the subject exhibits or is assumed to possess. Since the qualities, value, or possibility belong to or are characteristic of the subject, they are seen as existing "inside" the subject, whereby the word "contain" is once again used. What is noteworthy is that although a number of examples of this usage have been found in BNC, neither major online English dictionaries nor WordNet 2.1 have a relevant entry.

Usage 7 is interesting, for the subject is no longer inanimate as in the previous 6 usages, but is a human being or other animate being. The contained are feelings, emotions that they have. Since the feelings and emotions are felt arising out of the body, not from the outside, the word "contain" is used. However, the enclosed space does not simply refer to the human body, since human beings do not live in a vacuum free from the influence of society, tradition, politics, morality. It has always had broader implications. To "contain" feelings or emotions therefore does not simply mean to have them inside the body, but also to keep them within a limit. That limit is often defined by multiple factors, such as those mentioned above. It may reflect the long-standing distrust of human emotions in the West, where since ancient Greece people have had a tradition of exalting and eulogizing reason and moderation but distrusting emotions and excesses. The enclosed space has taken on social, moral, psychological, and even religious dimensions, rising above the physical and entering the sphere of the metaphysical. The Romantic poets who have been known for their flaunting of reason and the intensity of their emotions has drawn much criticism from the classicists and the conservatives. Recent studies have also tried to attribute the too intense emotions contained in their poems to mental instability or emotional disorder. Much discussion in this regard can be found in the heated debate in the academic field starting from mid-19th century and reaching an incredible white heat around the turn of the 20th century in fields involving literature, sociology, and particularly psychology and psychiatry.

Usage 8 seems most removed from the central sense of "contain". In this usage, the subject is an agent, while the object is an unfavorable condition, situation or state of affairs whose spread, expansion or influence has to be stopped or held back before further harm is done. Among the synonyms or near synonyms of the word in this sense are "check, turn back, arrest, stop, contain, hold back", according to WordNet 2.1. As can be seen from the examples given above and those in the Appendix, "contain" when used this way shows a predominant preference for words or phrases indicating unpleasantness, displaying a negative semantic prosody, according to Partington's categorization of semantic prosody (Partington, 1998). Violence, damage, unease, unrest, pressure are but a few examples. Usage 8 is therefore closer to Usage 7 than to any of the other usages of the word in that in both usages, the contained is something to be disliked or distrusted and has to be kept within a limit or stopped. The enclosed space is even harder to define than in Usage 7 and can vary from situation to situation.

From the above analysis, we can see that among the 8 usages or patterns in which the word "contain" appears, Usages 2 through 8 are all but extensions of Usage 1, either directly or indirectly. Their distance from that central sense appears to be increasing step by step. Although we cannot tell whether the word "contain" has taken on these senses one by one linearly in time or they have simply radiated out from the central sense, it is safe to conclude that the other usages are all shaped, to a real extent, by the first usage, which itself could have resulted from human beings' earliest bodily experience of the physical world, especially their experience of spatial orientation. The meanings of these collocations are far from arbitrary, but have been predetermined by the 
central sense "hold together, enclose". They can be seen as spatialization metaphors or what Johnson termed as "metaphorical projections".

\section{Conclusion}

The study of metaphors can be traced back to a thousand years ago when Aristotle mentioned it as a literary device, but it is quite recently that scholars like George Lakoff and Mark Johnson began to seriously consider its largely neglected use in everyday English. Lakoff and Johnson have found that human beings' conceptual system is largely metaphorical and they have ever since tried to develop their theories of conceptual metaphors, which have become an important part of cognitive linguistics. Inspired by these studies, the present paper aims at employing the theories developed by Lakoff and Johnson to throw light on how certain collocations or patterns of word use in English could have emerged due to human beings' metaphorical thinking. The word "contain" has been chosen and after a close examination of the patterns of its use as revealed by the British National Corpus, it is found that the word is frequently present in 8 patterns of use, called 8 usages in the paper. The first usage is believed to be based on the central sense of the word, derived from human beings' repeated bodily experience in the physical word; the 7 others are found to be related to that central sense in one way or another, but they all seem to have been shaped by that central sense. It is therefore believed that most of the usages of the word are but metaphorical projections of the image schemata.

A discovery of this kind is significant at least in two aspects. Firstly, it points out a direction in which cognitive linguistics and corpus linguistics can work together to reveal surprising facts about language use. Secondly, by uncovering how certain patterns of word use came into being and how they could be related to human beings' conceptualization of the world, EFL learners may gain more insights into many of the collocations in the English language and increase their understanding of the language and improve the accuracy of their language use.

\section{References}

Awaj, C. (2018). Examining the collocational knowledge of Libyan Arabic-speaking learners of English in different learning environments: classroom learning vs. naturalistic learning. Languages, 3(2), 16. https://doi.org/10.3390/languages3020016

Deignan, A. (2005). Metaphor and Corpus Linguistics (Converging Evidence in Language and Communication Research (Celcr). Amsterdam: John Benjamins Publishing Co. https://doi.org/10.1075/celcr.6

Firth, J. R. (1957). Papers in Linguistics. London: Oxford University Press.

Glynn, D., \& Fischer, K. (Eds). (2010). Quantitative Methods in Cognitive Semantics: Corpus-Driven Approaches Cognitive Linguistics Research (CLR). Mouton de Gruyter. https://doi.org/10.1515/9783110226423

Gries, S. T., \& Stefanowitsch, A. (2006). Corpora in Cognitive Linguistics: Corpus-Based Approaches to Syntax and Lexis. Walter de Gruyter. https://doi.org/10.1515/9783110197709

Johnson, M. (1987). The Body in the Mind: The Bodily Basis of Meaning, Imagination, and Reason. Chicago and London: The University of Chicago Press. https://doi.org/10.7208/chicago/9780226177847.001.0001

Lakoff, G., \& Johnson, M. (2003). Metaphors We Live By. Chicago: The University of Chicago Press. https://doi.org/10.7208/chicago/9780226470993.001.0001

Partington, A. (1998). Patterns and Meanings-Using Corpora for English Language Research and Teaching. Amsterdam/Philadelphia: John Benjamins. https://doi.org/10.1075/scl.2

Stefanowitsch, A., \& Gries, S. T. (2006). Corpus-Based Approaches to Metaphor and Metonymy. Walter de Gruyter. https://doi.org/10.1515/9783110199895

Teubert, W. (2010). A future of corpus linguistics. Contemporary Foreign Languages Studies, 3, 21-35; 62.

$\mathrm{Wu}$, J. H. (2014). Metaphor and collocation: a cognitive perspective in EFL teaching. US-China Education Review A, 4(5), 338-345.

Xiao, R., \& McEnery, T. (2006). Collocation, semantic prosody, and near synonymy: a cross-linguistic perspective. Applied Linguistics, 27(1), 103-129. Oxford: Oxford University Press. https://doi.org/10.1093/applin/ami045 


\section{Appendix}

Usage 1

1 of the nature of crime in Easton, most Land Rovers on routine calls only contain the driver and observer, both seated in the front, making some sort of

196 be used successfully for conservation programmes, provided they are kept free of pesticides and contain the plants on which butterflies feed, such as clover, thistles and stinging nettles

261 plasma that is kept hot enough by thermonuclear reactions, then the confinement system must contain the electrically-charged alpha particles that are produced by the fusion of deuterium and tritium.

Usage 2

36 \# Beaumaris was the last and largest of the castles built by Edward I to contain the Welsh begun in 1295 on a virgin site overlooking the Menai Strait, the

71 the saint's grave. In the church a carved stone shrine was erected to contain the saint's relics. This became the object of pilgrimage until the shrine was

121 booms across the Dee at the iron bridge on the Grosvenor Estate to try to contain the fuel, to which a red dye had been added to denote that it

176 the dough on greased baking sheets, raising the edges of each piece slightly to contain the topping. 5. Spoon the pizza sauce onto the dough and top with

271 dollars so far, using arrays of magnets as big as houses in order to contain the fuel at temperatures ten times hotter even than those in the centre of the

301 only a tight white brassire above her skirt. It seemed almost too small to contain the swelling plumpness of her upper body. It crushed and lifted her breasts to

306 you oblige? 'Reluctant to refuse, Bloxham went in search of something to contain the carcass.' I see no reason for us to sit and watch,

421 to 8DGH. At either end of the aquarium I placed two terracotta dishes to contain the fish's food. I intended to feed a certain amount of high protein

Usage 3

46 result of investigating unsolved problems in biology, including how a seed or egg can contain the essence which grows into the new individual member of the same species, he

51 higher HDLs. This is due to their large consumption of Omega-3 fatty acids which contain the polyunsaturated fats EPA (eicosapentaenoic acid) and DHA (docosahexoenic acid).

66 cholesterol, and raising its level in the blood. Both saturated and polyunsaturated fats contain the same amount of calories. Finally, cholesterol is a specialized form of fat

101 drank water originating from the Farmoor reservoir near Oxford, which has been found to contain the cryptosporidium organism. (SP:PS5XP) I went to the doctor on the Saturday and he

131 Croton sublyratus, which is used in traditional medicine, has recently been found to contain the antiulcer acyclic terpenoid plaunotol (17) which is similar in structure to gefarnate

136 that spore contained the mutant gene, all the cells of the new plant will contain the mutant gene. If the spore did not, they will not. Cells

141 transplantation. While the nuclear transplantation and other experiments make it clear that all nuclei contain the same genetic information, there are exceptions. In certain worms, for example

156 people can get instant answers to their problems. The back-up pack should perhaps contain the leaflet you sent to us. \# We propose the following format for Forth RFM

186 (fig. 2) \# ORGANIC OXYGEN COMPOUNDS \# Alkanols (alcohols) Alkanols both contain the -OH, hydroxyl group Primary alkanols have no more than one alkyl group attached

191 In its amalgamated form, the Physical and Theoretical Chemistry Laboratory will contain the Dr Lee's and Coulson Professors, the ad hominem Professor of Electron Spectroscopy

206 and $3.0 \mathrm{~kb}$ ). The $13.5 \mathrm{~kb}$ fragment is present in all phenotypes that contain the A haplotype and is absent in the B haplotype. In contrast, four

231 Other very distinctive thin sections were found for vessels with a distinctive rilled decoration which contain the minerals feldspar, mica and quartz: these are fragments of a granite.

251 arrived in the area over 7,000 years ago. Grey silts on the valley floor contain the abundant remains of salt marsh plants suggesting that at that time this was a

256 cocoa is short on genetic variability. Wild plants, in the Amazon, may contain the required genes. The first problem, is to find them \# John Allen

281 with a more restricted tissue distribution than the Sos proteins. This protein does not contain the proline-rich sequences that couple Sos to Grb2 and hence to receptor tyrosine kinases.

286 you need. Initially at any rate, it is best to choose packs that contain the types of component which can be found in practically every project. The obvious

316 one stroke the water will cease to contain the salt, and the salt will contain the water. The Chases drive out to spend the weekend with them. Then

336 found, but they occur in abundance. Sometimes they occur with cherty rocks that contain the remains of indubitably planktonic 
radiolaria. Some, at least, of the graptolitic

346 cells, the glia cells of the peripheral nervous system, lack N-Oct proteins but contain the Oct-6 protein in addition to the Oct-1 protein 35 . The early and abundant

351 within the HPV-16 URR was deleted. Hence in cells such as HeLa cells which contain the cervical protein, the octamer motif acts as a positive element both in the

361 sequences at each of the duplicated ZNF gene loci. Five of the eight YACs $\underline{\text { contain the }} 4.0 \mathrm{~kb}$ EcoRI KOX2-hybridising fragment indicative of ZNF11A in 10p11.2, and therefore contain

366 containing DH I and II ( $2.0 \mathrm{~kb} 5$ ' of Ea) does not contain the appropriate elements to isolate the transgene from adverse chromatin effects, or does not

381 and over (see Table 6.8). For men the older age groups also contain the highest proportions of ex-regular smokers. The data describing the prevalence of smoking illustrates

391 replaced in any sentence, without syntactic change, by a word which does not contain the affix: Her kindness (voice) was overwhelming. I found them extremely

441 , the gear-shift level must exist within the gearbox/passenger compartment intersection, which itself must contain the discrete sub-spaces of movement envelopes which are associated with functions of the gearbox.

481 lotions would be displayed in simple bottles of all shapes and sizes and which would contain the natural ingredients she had come across during her trips to remote communities. Personal

\section{Usage 4}

81 only be used in modules of type FOREIGN. Other types of module must not contain the 'FOREIGN-SET-IS' keyword, nor any user-supplied entries. It is used to

86 process is not running. The command file to be submitted as a batch should contain the following: where \#<config filename $>$ is the full pathname of the configuration file

91 : 'directory'. It is estimated that a database of this size could contain the following (note that these figures are only estimates): these figures equate

201 my Noble Friend said that he'd looked up Hallsbury but that it didn't contain the right words, er er I rather wonder whether he looked up so to

216 contains only 'For'verses after verse 295 (ending in verses 695 to 768 which contain the celebrated passage' I will consider my Cat Jeoffry', an animal Smart

291 the texts which Lanfranc had quoted in 1072- and, of course, they now contain the forged additions. Both he and Eadmer had written their Histories down to 1120

296 and employer organisations. \# Annex 1 \# Structure of Module Descriptors \# Module Descriptors contain the following information and advice: \# Catalogue Reference \# This allows the easy identification

321 She welcomed the tea she made and said, when her daughter could no longer contain the fact of her marathon,' Oh there was no need to hurry like

406 it, can try nevertheless to come up with something which is interesting, can contain the' Hey, this is for you,' for the audience, along

466 ). While the onus is on the defence, most police officers' statements contain the question' Are you insured to drive this motor vehicle?' In the

Usage 5

11 the pleadings. The pleadings are somewhat convoluted but must be referred to because they contain the facts, as is normal in a demurrer. They open with a declaration

16 can be insurmountable. \# 8.3 Essential elements of an expert clause Expert clauses should contain the items in this list, which also shows where to find discussion in the

26 . \# 4. Registered land-application for official searches (a) What the Registers contain $\underline{\text { The }}$ three registers that make up the Entries on the Register- the Property Register

31 avoid it if it can be shown that the written document was not intended to contain the whole of the parties' agreement (J Evans and Son (Portsmouth)

56 was not repeated in later editions. A number of editions of Coverdale's translation contain the curious reading at Jeremiah viii.22:' there is no more Triacle treacleat Gilead

76 may be run in batch mode by submitting a command file. This file should contain the responses the user would have given to the prompts had the system been used

96 \# Following endorsement, the SSR is distributed to the managers of further packages which contain the endorsed package(s). \# Endorsement rejected successfully \# The rejection of the endorsement of the

146 the trainees a copy of the next two handouts as they appear. The handouts contain the main points you need to make. At the end of the session spend

151 the Personnel Committee concerning the possible extension of sickness allowance. This report will also contain the medical adviser's opinion of the employee's medical condition and future fitness to

166 or Sched 4 applies. The request for summons and the particulars of claim must contain the certificates required by Ord 3, r 3(5) -(8) or $\mathrm{r}$

171 he would not be prepared to support the present EMU treaty, which does not contain the provisions and safeguards that he has mentioned? Can he confirm that he does 
266 assuming enough countries follow the UNIDO format-is that proposals from many nations all contain the same essential data. Machines made by Apple are the only microcomputers that can

341 solutions of (11.7) or (11.13). These equations, however, contain the derivatives of U, and hence they depend on the arbitrary functions $\mathrm{f}(\mathrm{u})$ and

376 one area he was fortunate enough to gain access to doctors' lists, which contain the names of most of the population since nearly everyone of every age is registered

426 comprehensive guide on how to choose the right shoe for you The next six pages contain the most comprehensive listings of running shoes available. To some, it's a

456 wording of the report. If there was a serious disagreement the report would still contain the point but it would say that the school disagreed with it for whatever reason

491 of credit for presentation to the issuing or confirming bank. Such a copy would contain the statements or notations necessary to reassure the beneficiary and letter of credit bank that

496 will deal with the voting rights attaching to each class of shares. They will contain the pre-emption provisions and possibly a list of matters that can be dealt with only

501 if they are to be relied upon. Similarly any predictions from syntactic analysis must contain the correct code. It may be found from testing that this is impossible to

Usage 6

21 for each pupil. Effective learning requires a certain simplicity of structure in which to contain the openness and indefiniteness of all genuine learning. Furthermore, this "essence"

111 or incident in the first half of the month or around the 27 th may well contain the seeds of something far greater. Certainly, Venus protects your interests while the planetary

161 The question thus with which we are confronted is that of whether this religion can contain the new consciousness of women. I shall in this chapter first look at the

236 between the two communities. In 1842, the European proposal — which was to contain the seeds of so much grief in the next century-was accepted by the

241 example, has already been affected by that individual's electrical impulses. It will contain the thoughts and emotional imprints of the person. All objects have this information of

246 as that of the Daily Express at its peak (around 1960), might contain the seeds of decline. Both the Express and the Mail went into the 1970 s

386 themes and counter-themes may at any one time resemble undeveloped seeds, in that they contain the possibilities for future argumentative responses, including those son of reversals when the Side

401 deadly poison. And when the poison was put under the microscope it seemed to contain the most beautiful colours of the rainbow. A most attractive thing, and yet

411 to be considered reasonable value. Third, the target bank's business mix must contain the inherent value to repay the premium that the acquirer will have to pay to

431 attributes, a part of the price of each drawing will remain unexplained, and contain the influence of time (the trend, if any), as well as

Usage 7

311 Mortimer reholstered his gun, satisfied at a job well done, and striving to contain the excitement he felt at the combat. He spotted a familiar face, and

Usage 8

6 Order Act, which became law on 1 January 1937, in an attempt to contain the situation. The Public Order Act represented the culmination of a long debate within

61 received the news of the Emperor's decision with typical Dwarf stoicism. Unable to contain the Goblin Warlord's ambitions, the Dwarfs resolved to shut their stout doors and

106 count in the end, though, for try as she might Mills could not contain the might of Italy's Emanuela Pierantozzi, the European champion, who stood a

116 Helmut Kohl's government, which has been accused of not trying hard enough to contain the wave of Right-wing violence. The opposition Social Democrats called for neo-Nazi arsonists to

126 to $315 \mathrm{p}$. Argos said it would be important over the coming 12 months to contain the additional cost pressures from the pound's devaluation. \# Business split over Budget

211 constant fuel supply. All stressed skin structures exhibit a minimum surface tension that can contain the applied forces. Some of their characteristics can be observed in soap bubbles and

221 the religious sphere when one of the problems faced by institutionalized orthodoxies has been to contain the eruption of reform and sectarian revolt. There may be no obvious equivalent in

226 the Glorious Revolution William was able to commit England to a continental alliance designed to contain the expansionism of Louis XIV's France, and to preserve the balance of power

326 return it.' Theda had perforce to let go, for she could not contain the hair now it had sprung in so disorderly a way from its moorings.

331 he was clear. Without delay, the fire-fighters gave up the unequal struggle to contain the leaping flames. Shutting down their pumps, they began hastily reeling in their 
371 themselves or their property. Improved police methods might help, writes Harrison, to contain the problem. But, without other changes, the result is likely to be

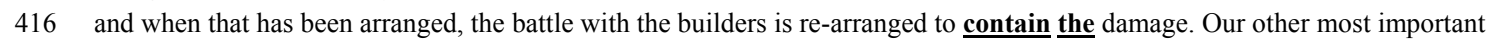
venture is our association with the financier,

436 , the plant produces extra, and usually extremely characteristic, growth in order to contain the invader, and limit its damage. One of the best known is the

451 will be to adopt more of the North's repressive emergency measures in order to contain the violence. Bit by bit the ignorance of, and lack of respect for

461 of aggression, and there are teachers whose daily lives are an eternal battle to contain the unease that noise calls forth in them. Teachers report themselves becoming punitive and

471 's Aug. 13 visit to Iraq for talks with Saddam Hussein, his efforts to contain the dispute within the Arab world had failed and he was directing his efforts at

476 security forces. The protests continued and in early April, in an effort to contain the mounting unrest, King Birendra dismissed the Prime Minister, Marich Man Singh Shrestha

486 healthy slice of the market? \# Daniel Butler' We're just trying to contain the market at the moment—at least until we've got the capacity to

Uncategorized

41 by the animals and machines that harvest the crops it bears. Finally it will contain the facilities to repair and rebuild itself should any combination of climate, beast,

276 -galactosidase A gene and the remaining three (1G5, 2F10 and 1B2) contain the ATK locus. The ATK locus encompasses a 20-kb genomic region located $50-70 \mathrm{~kb}$ centromeric

356 simplest computation is achieved by comparing the weights of successive (deleted:figure) withdrawals. As both contain the same quantity of dispersant the difference represents the weight within the size interval concerned

396 the result of continuities and exclusions recognised (and desired) by editors anxious to contain the play, to create a singular text where more than one exists. Most

446 translation and three of rotation). This "technical" work space may also contain the graphical derivatives of any or all of the primary functions (to give all

506 are to form a constitutive relation for the material of the rod it must not contain the dimensions.) The first ad simplest relation between stress and deformation gradient would

511 hold the line segment data and the second, opened on unit 11, will contain the polygon definitions. The polygon definition file will be used in a later program

\section{Copyrights}

Copyright for this article is retained by the author, with first publication rights granted to the journal.

This is an open-access article distributed under the terms and conditions of the Creative Commons Attribution license (http://creativecommons.org/licenses/by/4.0/). 